ZOOLOGIA 27 (3): 440-444, June, 2010

doi: $10.1590 /$ S1984-46702010000300017

\title{
Notes on the neotropical genus Macrinus (Araneae: Sparassidae)
}

\author{
Cristina A. Rheims
}

Laboratório de Artrópodes, Instituto Butantan. Avenida Vital Brazil 1500, 05503-900 São Paulo, São Paulo, Brazil.
E-mail: cris.rheims@butantan.gov.br

\begin{abstract}
Macrinus Simon, 1887 can be diagnosed by the twisted tegulum with a distal retrolateral laminar projection and the fulcrum with a prolateral serrated projection on the male palp and by the copulatory ducts with an anterior, fused hyaline part and a median long and sclerotized part ending at a slightly rounded spermathecae in the female epigynum. The genus currently includes three species: Macrinus succineus Simon, 1887 and M. jaegeri Rheims, 2007, from Brazil, and M. pollexensis (Schenkel, 1953) from Venezuela. In this paper I describe two new species: Macrinus bambuco sp. nov. and Macrinus calypso sp. nov. The first is based on a male from Lomalinda, Colombia, and is distinguished from the remaining Macrinus by the presence of a retrolateral triangular projection on the tegulum of the male palp. The second is based on a male from Charlotteville, Tobago, and is distinguished from the remaining species by a small retrolateral process at the base of the RTA. In addition, Olios mohavensis Fox, 1937, from the Mojave Desert in California, USA, is transferred to Macrinus. The species can be distinguished from the remaining species of the genus by a median anterior constriction on the anterior margin of the median septum of the female epigynum. It's distribution range is extended to southwestern North America, in the Nearctic region. No Macrinus species is known to occur in Central America.
\end{abstract}

KEY WORDS. Macrinus bambuco sp. nov.; Macrinus calypso sp. nov.; Macrinus mohavensis; taxonomy; transfer.

Sparassidae Bertkau, 1872 is a large and widespread spider family, including over 1,000 species distributed in 83 genera (Platnick 2010). Of these, over 150 species in 23 genera have distribution ranges that include the Neotropical region (PLATNICK 2010), which has recently been receiving growing attention. Seven genera were revised (RHEIms 2007, 2008, RHEIMs \& JäGER 2008, JÄGER \& Rheims 2008) one synonymized (Rheims 2008) and two transferred to Sparassidae from other families, Adcatomus Karsch, 1880 from Clubionidae (JäGER 2000) and Quemedice Mello-Leitão, 1942 from Philodromidae (Rherms et al. 2008).

Macrinus Simon, 1887 was recently revised and includes at present only three species restricted to South America (RHeIms 2007, Platnick 2010). Macrinus succineus Simon, 1887 was originally described from São Paulo de Olivença, state of Amazonas, Brazil and its distribution range covers western South America, from northern Guyana to southeastern Brazil. Macrinus pollexensis (Schenkel, 1953) was described from El Pozon, Fálcon, Venezuela and its distribution range covers mostly eastern South America, from Venezuela to southeastern Brazil. The third and recently described Macrinus jaegeri Rheims, 2007 has a more central distribution, with records from the states of Pará and Mato Grosso, Brazil (Rheims 2007).

While examining material from North, Central and northern South America, deposited in some of the largest American museums (American Museum of Natural History, National Museum of Natural History in the Smithsonian Institution,
Museum of Comparative Zoology and California Academy of Sciences), I came across the type specimen of Olios mohavensis, described by Fox (1937) from the Mojave Desert in California. Despite the fact that no other Macrinus specimens were found amongst the Central and North American material and no species is known to occur outside South America, the study of the female genitalia showed that this species is clearly congeneric with M. succineus and should thus be transferred to that genus. The species is herein redescribed and illustrated in detail. Further investigation and sampling carried out in the type locality might shed some light as to how this species landed in the middle of the Desert and why there are no Macrinus recorded from Central America.

In addition, two new species are described, one from Lomalinda, Colombia, and one from Charlotteville, Tobago, increasing the genus composition to six species and extending it's distribution range to southwestern North America.

\section{MATERIAL AND METHODS}

The specimens dealt with in this paper are deposited in the National Museum of Natural History, Smithsonian Institution (USNM, curator: J. Coddington) and California Academy of Sciences (CAS, curator: C.E. Griswold).

Morphological observations and illustrations were made using a Leica MZ12 stereomicroscope with a camera lucida. 
Measurements were taken with a micrometric ocular and are given in millimeters. Female epigynum was dissected and submerged in clove oil to study internal structures.

Format of descriptions follows Rheims (2007). Spine notation follows Petrunkevitch (1925). Leg measurements are listed as: total length (femur, patella, tibia, metatarsus, tarsus); eye diameters as: AME, ALE, PME, PLE; and interdistances: AMEAME, AME-ALE, PME-PME, PME-PLE, AME-PME, ALE-PLE.

\section{TAXONOMY}

\section{Macrinus Simon, 1887}

Macrinus Simon, 1887: 470 (type species by original designation: M. succineus Simon). Caporiacco, 1955: 404; Rheims, 2007: 159; Platnick, 2010. Sparassus Walckenaer, 1805: 39; Simon, 1897: 37 (in part). Olios Walckenaer, 1837: 202; Petrunkevitch, 1911: 503 (in part).

Diagnosis. Species included in Macrinus are distinguished from the remaining Sparassidae by the twisted tegulum (Fig. 4; RHeIMs 2007: figs 22, 28, 34) with distal retrolateral laminar projection (Fig. 5, LP; RHeIMs 2007: figs 23, 29, 35) and a fulcrum with a prolateral serrated projection (Figs 3-4, F, SP; RHeIMs 2007 : figs $17,18,21,27,33)$ on the male palp. Females are distinguished by the copulatory ducts with an anterior, fused hyaline part and a median long and sclerotized part ending at a slightly rounded spermathecae (Fig. 2; Rherms 2007: figs 25, 31, 37).

Description. Recently redescribed by Rheims (2007: 159).

Distribution. Mostly Neotropical. Known from Tobago and Venezuela to southeastern Brazil. One species recorded from California, in the Nearctic region

Composition. Macrinus succineus, M. pollexensis, $M$. jaegeri, M. mohavensis comb. nov., M. bambuco sp. nov., and M. calypso sp. nov.

\section{Macrinus mohavensis (Fox, 1937), comb. nov.}

Figs $1-2$

Olios mohavensis Fox, 1937: 466 (Female holotype from Mohave Desert $\left[35^{\circ} 24^{\prime} \mathrm{N} ; 115^{\circ} 35^{\prime} \mathrm{W}\right]$, California, United States, deposited in USNM 1273, examined); Roewer, 1954: 711; Bonnet, 1958: 3174; Platnick, 2010.

Diagnosis. Females of M. mohavensis are distinguished from those of the remaining species of the genus by the anterior margin of the median septum with a median constriction (Fig. 1).

Description. Male unknown.

Female (Holotype - USMN). Prosoma orange brown, slightly darker at cephalic region and along fovea. Chelicerae slightly darker than prosoma. Labium and endites orange, distally pale yellow. Sternum orange with darker, slightly sclerotized margins. Legs and pedipalps orange. Opisthosoma yellowish gray with conspicuous, cream colored cardiac impression. Total length 15.3. Prosoma: 6.15 long, 6.0 wide. Opisthosoma: 8.85 long, 5.4 wide. Eye diameters: 0.39, 0.36, 0.24, 0.36; interdistances: $0.33,0.15,0.57,0.57,0.39,0.33$. Chelicerae with 2 promarginal and 4 retromarginal teeth, the basal one smaller than the remaining three. Leg measurements (2143): I: 27.15 (7.5, 3.15, 7.05, 7.5, 1.95); II: 27.9 (8.1, 3.15, 7.05, 7.65, 1.95); III: $21.6(6.9,2.55,5.4,5.25,1.5)$; IV: $24.0(7.35,2.55,6.0,6.45$, 1.65). Leg spination: femora I-III: d0-1-1; p1-1-1; r1-1-1, femur IV: d0-1-1; p1-1-1; r0-0-1, tibia I-IV: p1-0-1; r1-0-1; v2-2-0, metatarsus I-III: p1-1-0; r1-1-0; v2-2-0, metatarsus IV: p1-1-1; r1-1-1; v2-2-0. Epigynum divided into a pair of smooth and slightly rounded lateral lobes partially covering an anteriorly truncated median septum and with anterior pair of copulatory openings. (Fig. 1). Fertilization ducts short and hook-shaped (Fig. 2).

Distribution. Known only from the type locality.

\section{Macrinus bambuco sp. nov.}

Figs 3-5

Type specimen. Male holotype from Lomalinda $\left(03^{\circ} 18^{\prime} \mathrm{N}\right.$; $73^{\circ} 22^{\prime}$ W), Puerto Lleras, Meta, Colombia, B.T. Carroll, V. \& B. Roth leg., deposited in CAS.

Diagnosis. The males of M. bambuco sp. nov. are distinguished from those of the remaining species of the genus by the RTA strongly bent ventrally (Fig. 5) and by the presence of a retrolateral triangular projection on the tegulum of palp (Fig. $4, \mathrm{TP})$.

Description. Male (Holotype, CAS). Prosoma orange brown, slightly darker at eye area, with brown fovea and thoracic striae. Chelicerae reddish brown. Legs and pedipalps orange brown. Sternum brown with dark orange margins. Labium brown, distally orange. Endites brown with rounded orange mark at base and distally orange. Opisthosoma dorsally brownish gray with faint cardiac impression. Ventrally with median longitudinal gray band. Total length 20.8. Prosoma: 9.6 long, 8.8 wide. Opisthosoma: 10.8 long, 7.0 wide. Eye diameters: $0.78,0.64,0.50$, 0.56 ; interdistances: $0.24,0.08,0.76,0.70,0.40,0.40$. Chelicerae with 2 promarginal and 4 retromarginal teeth, the basal one smaller than the remaining three. Leg measurements: I: 54.3 (14.8, 5.1, 14.3, 16.0, 4.1); II: 56.1 (15.3, 5.2, 15.2, 16.1, 4.3); III: 44.5 (13.4, 4.3, 12.0, 11.8, 3.0); IV: 49.1 (14.4, 4.2, 13.5, 13.6, 3.4). Spination: femora I-III: p1-1-1; d0-1-1; r1-1-1; femur IV: p1-1-1; d0-1-1; r0-0-1; tibia I: p1-0-1; d0-0-1; r1-0-1; v2-2-0; tibiae II-IV: p1-0-1; r1-0-1; v2-2-0; metatarsi I-IV: p1-1-0; r1-1-0; v2-2-0. Palpal tibia with one prolateral and one retrolateral spine. RTA conical and strongly bent ventrally at the middle (Fig. 5). Tegulum Sshaped, slightly spiraled perpendicularly to the main palpal axis, towards the tip of the cymbium with small, medial, retrolateral, triangular projection (Figs 3-5). Distally with retrolateral laminar projection (Fig. 5) and a prolateral serrated projection (Fig. 3). Embolus filiform, anteriorly curved backwards (Figs 3-5).

Distribution. Only known from the type locality.

Etymology. The specific name is a noun in apposition that refers to Colombian folk music. The rhythm is sometimes said to be the unofficial music of Colombia and has a widespread popularity throughout Latin America. 

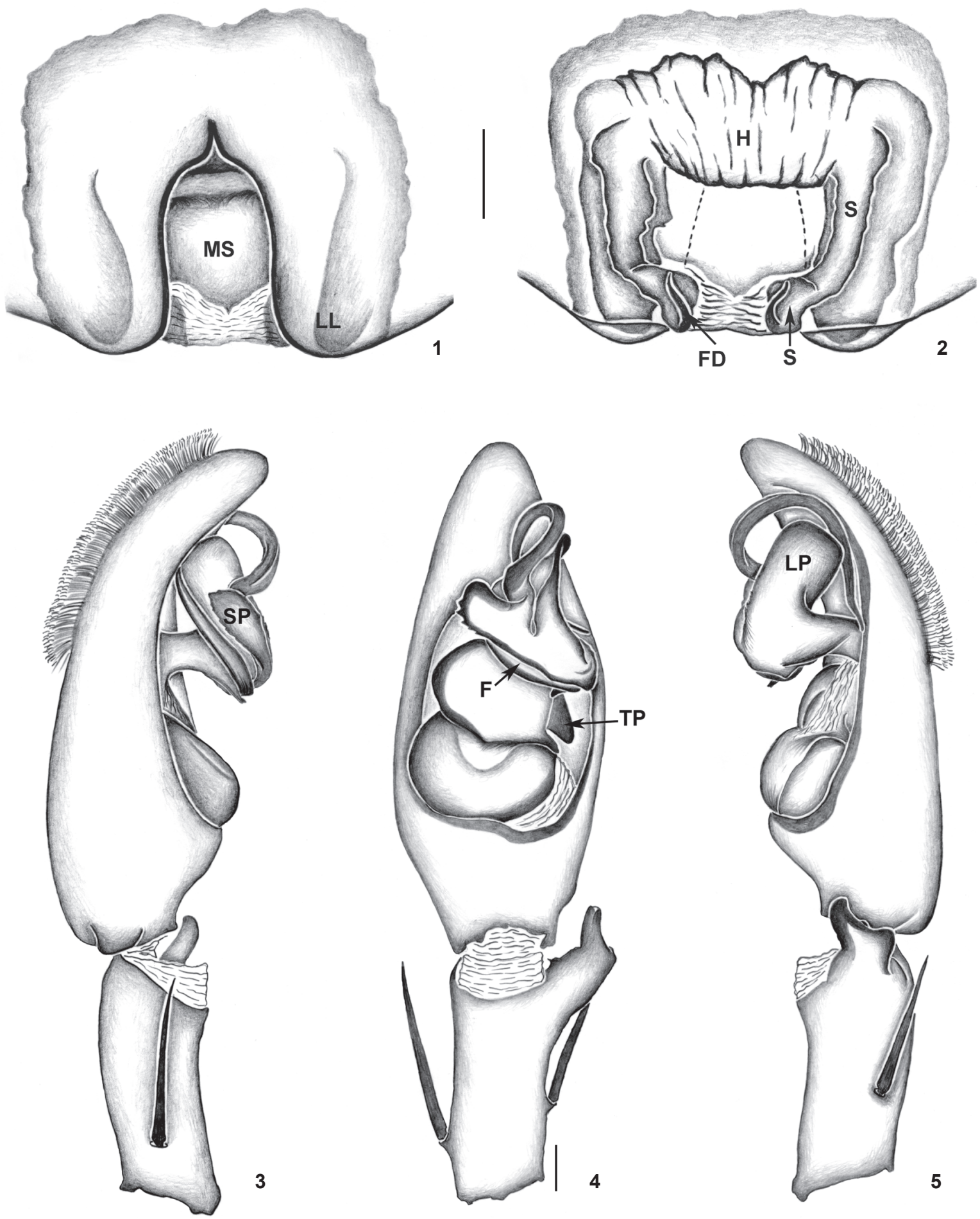

Figures 1-5. 1-2 Macrinus mohavensis (Fox) comb.nov.: (1) female, epigynum, ventral view; (2) vulva, dorsal view; 3-5. Macrinus bambuco sp.nov.: (3) male, left palp, prolateral view; (4) ditto, ventral view; (5) ditto, retrolateral view. (F) Fulcrum, (FD) Fertilization duct, (H) hyaline part of copulatory duct, (LL) lateral lobes, (LP) laminar projection, (MS) median septum, (S) sclerotized part of copulatory duct, (S) spermathecae (SP) serrated projection, (TP) triangular projection. Scale lines: $0.5 \mathrm{~mm}$. 


\section{Macrinus calypso sp. nov.}

Figs 6-8

Type specimen. Male holotype from Flagstaff Hills [11 $\left.11^{\prime} \mathrm{N} ; 60^{\circ} 32^{\prime} \mathrm{W}\right]$, Charlotteville, Ward of Tobago, Tobago, 24.IX.2008, J.N. Sewial, C.K. Star, D. De Roche, D. Hardy \& I. Bragg leg., deposited in USNM.

Diagnosis. Males of M. calypso sp. nov. are distinguished from those of the remaining species of the genus by the small process at the retrolateral base of the RTA and by the retrolateral keel on the tegulum of the male palp (Figs 6 and 7).

Description. Male (Holotype, USNM). Prosoma pale yellow, light brown along fovea and thoracic striae and margins of cephalic region. Eye area reddish orange. Clypeus dark brown. Chelicerae yellowish orange. Legs and pedipalps orange. Ster- num pale yellow with pale orange margins. Labium orange, distally pale yellow. Endites yellow, distally cream colored. Opisthosoma pale yellow. Dorsally with conspicuous orange heart mark. Ventrally with longitudinal, median yellow stripe. Total length 21.0. Prosoma: 8.2 long, 10.0 wide. Opisthosoma: 12.8 long, 8.6 wide. Eye diameters: $0.78,0.62,0.46,0.52$; interdistances: $0.40,0.12,0.76,0.80,0.48,0.36$. Chelicerae with 2 promarginal and 4 retromarginal teeth, the basal one smaller than the remaining three Leg measurements (: I: 68.2 (18.4, 6.0, 18.0, 20.4, 5.4); II: 72.4 (19.8, 6.4, 19.4, 21.6, 5.2); III: 57.4 (16.8, 5.2, 16.2, 15.4, 3.8); IV: 43.5 (16.8, 4.2, 15.0, 16.8, 4.2). Spination: femora I-II: p1-1-0; d0-1-1; r1-1-1; femur III: p1-1-1; d0-1-1; r1-1-1; femur IV: p1-1-1; d0-1-1; r0-0-1; tibia I-II: p1-01 ; d0-0-1; r1-0-1; v2-2-0; tibia III-IV: p1-0-1; r1-0-1; v2-2-0; metatarsi I-III: p1-1-0; r1-1-0; v2-2-0; metatarsus IV: p1-1-2; r1-
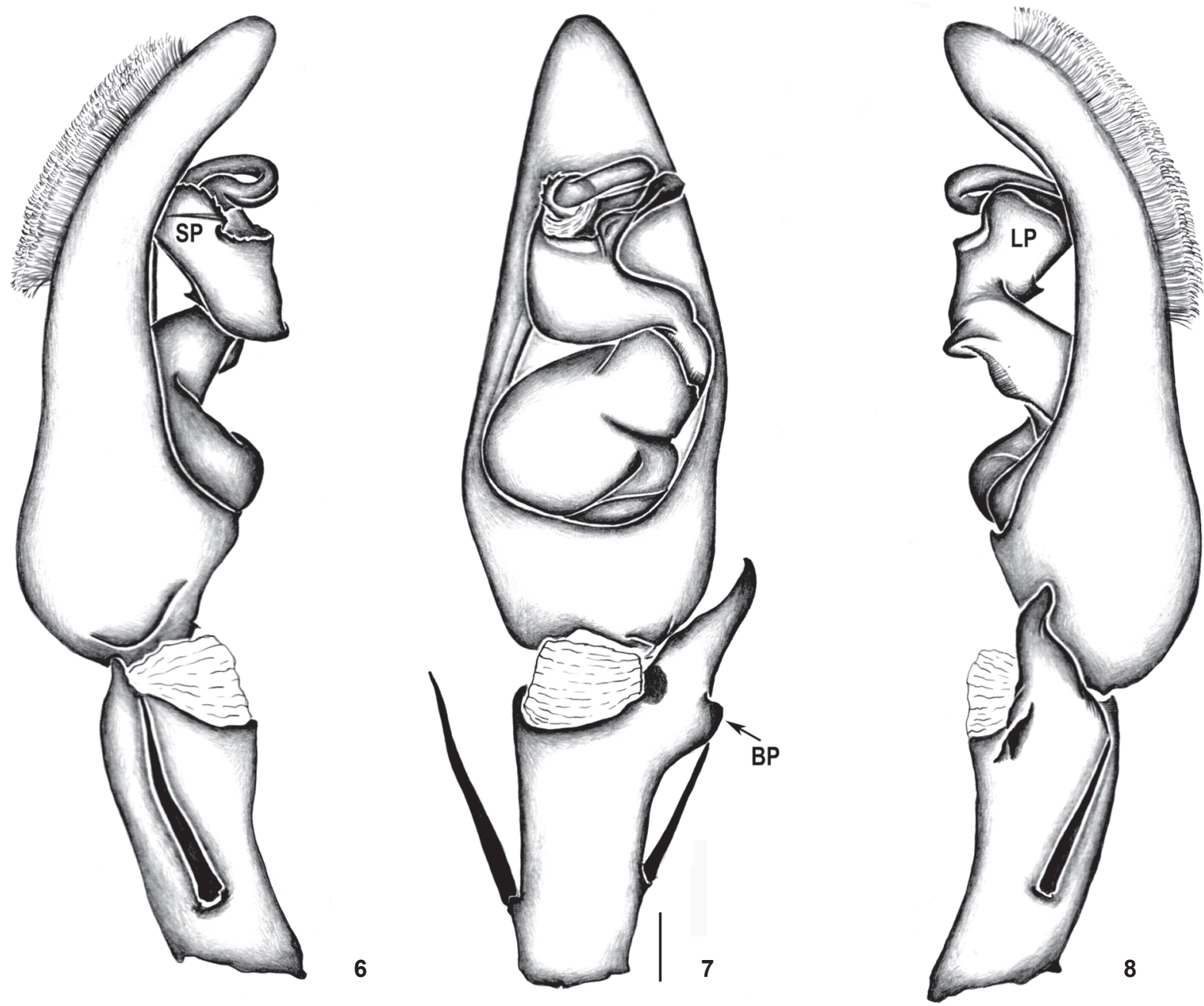

Figures 6-8. Macrinus calypso sp.nov.: (3) male, left palp, prolateral view; (4) ditto, ventral view; (5) ditto, retrolateral view. (BP) Basal process of RTA, (LP) laminar projection, (SP) serrated projection. Scale line $=0.5 \mathrm{~mm}$. 
1-1; v2-2-0. Palpal tibia with one prolateral and one retrolateral spine (Figs 6-8). RTA conical, slightly bent dorsally at tip, and with small retrolateral process at base (Figs 7 and 8). Tegulum S-shaped, slightly spiraled perpendicularly to the main palpal axis towards the tip of the cymbium (Figs 6-8). Retrolaterally with a medial small keel (Figs 7 and 8). Distally with a prolateral serrated projection (Fig. 6) and a retrolateral laminar projection (Fig. 8). Embolus filiform, anteriorly curved backwards (Figs 6-8).

Etymology. The specific name is a noun in apposition that refers to the folk music from Tobago.

\section{ACKNOWLEDGEMENTS}

I wish to thank Antonio D. Brescovit for critical comments on this manuscript. This study was supported by the Ernst Mayr Grant, from the Museum of Comparative Zoology at Harvard University, the Theodore Roosevelt Memorial Fund and Fundação de Amparo à Pesquisa de São Paulo (FAPESP 06/ 61167-6).

\section{LITERATURE CITED}

BonNET, P. 1958. Bibliographia araneorum. Toulouse, 2 (4): 3027-4230.

Caporiacco, L. Di. 1955. Estudios sobre los aracnidos de Venezuela. 2a parte: Araneae. Acta Biologica Venezuelica 1: 265-448.

Fox, I. 1937. The Nearctic spiders of the family Heteropodidae. Journal of the Washington Academy of Science 27: 461474.

JÄGER, P. 2000. On Adcatomus ciudadus Karsch 1880, a remarkable spider species from Lima, with comments on South American Sparassidae (Arachnida, Araneae). Mitteilungen aus dem Museum für Naturkunde in Berlin 76: 237-242.

Jäger, P. \& C.A. Rheims 2008. On the genera Origes Simon 1897, Prusias O. Pickard-Cambridge 1892, Tibellomma Simon 1903 and Paenula Simon 1897 from South and Central America. Senckenbergiana biologica 88: 29-39.

Submitted: 15.X.2009; Accepted: 02.III.2010.

Editorial responsibility: Antonio Domingos Brescovit
Petrunkevitch, A. 1911. A synonymic index-catalogue of spiders of North, Central and South America with all adjacent islands, Greeland, Bermuda, West Indies, Terra del Fuego, Galapagos, etc. Bulletin of the American Museum of Natural History 29: 1-791.

Petrunkevitch, A. 1925. Arachnida from Panama. Transactions of the Connecticut Academy of Arts and Sciences 27: 51248

PlatniCK, N.I. 2010. The world spider catalog, version 10.5. American Museum of Natural History. Available online at http://research.amnh.org/entomology/spiders/catalog/ index.html [Accessed: 02/VI/2010]

Rheims, C.A. 2007. Revision of the Neotropical spider genus Macrinus (Araneae, Sparassidae). Journal of Arachnology 35: 159-170.

Rherms, C.A. 2008. On the Neotropical genus Adcatomus Karsch (Araneae: Sparassidae). Zootaxa 1809: 61-66

Rheims, C.A. \& P. Jäger. 2008. Revision of the Neotropical huntsman spider genus Vindullus Simon (Araneae, Sparassidae). Journal of Arachnology 36: 221-231.

Rheims, C.A.; F.M. Labarque \& M.J. Ramírez. 2008. The South American genus Quemedice Mello-Leitão (Araneae: Sparassidae): familial placement and taxonomic revision. Zootaxa 1813: $60-68$

Roewer, C.F. 1954. Katalog der Araneae von 1758 bis 1940, vol. 1. Institut Royal des Sciences Naturelles de Belgique, Bruxelles.

Simon, E. 1887. Espèces et genres nouveaux de la famille des Sparassidae. Bulletin de la Société zoologique de France 12: 466-474.

SIMON, E. 1897. Histoire naturelle des araignées. Paris, vol. 2, $192 \mathrm{p}$.

Walckenaer, C.A. 1805. Tableau des aranéides ou caractères essentiels des tribus, genres, familles et races que renferme le genre Aranea de Linné, avec la désignation des espèces comprises dans chacune de ces divisions. Paris, 88p.

WaLCKENAER, C.A. 1837. Histoire naturelle des insectes Aptères. Paris, vol. 1: 1-682. 